\title{
Lo que en los libros no se ve Un elogio del viaje
}

\author{
Enrique Granell
}

Recibido 2018.06.21 ::: Aceptado 2018.07.04

DOI: 10.5821/palimpsesto.18.5668

1 erederas del racionalismo ilustrado las universidades y politécnicos del siglo diecinueve organizaron sus estudios desmenuzando los contenidos de cada una de las disciplinas en asignaturas. Con ello se creía que se optimizarían y que podrían universalizarse los resultados de una enseñanza positivista que por vez primera en la historia se ofrecía y necesitaba de un gran número de estudiantes.

Fue un tema muy propio de su tiempo. Llevó los análisis y la disección de los saberes a su máxima expresión. La química se disolvió en la tabla periódica de elementos, el derecho en sus diferentes códigos, la frase en sus componentes gramaticales. La eficacia que se pretendía alcanzar quedó convertida en método, casi podríamos decir en el verdadero estilo de su siglo.

Pero la verdadera pregunta era si ese amasijo de componentes diversos que se creían complementario y que en realidad eran tan dispares podrían en algún momento alcanzar la vida verdadera. Como en los relatos de Frankenstein se necesitaba una energía desconocida hasta entonces que insuflase movimiento a lo inerte, que convirtiese en animado un organismo artificial.

La arquitectura y su enseñanza no escaparon a este proceso. Los programas de unos nuevos edificios públicos cada vez más laberínticos empezaron intentando encamisarse en los de los más complejos conocidos hasta entonces, las termas romanas y los monasterios medievales, pero tras comprobar la imposibilidad del método se pasó también a desmenuzarlos hasta convertirlos en una suma de espacios singularizados por su uso y a colocarlos sobre unas redes geométricas estrictamente jerarquizadas por ejes ortogonales. Es lo que conocemos como sistema Beaux-Arts.

También los programas de enseñanza trituraron la arquitectura en componentes. La sometieron a asedio desde el dibujo, el ornamento, la construcción, la teoría de las artes y los proyectos, llamados en un principio "de conjunto", a los que se les adjudicaba la responsabilidad de intentar insuflar la energía necesaria para regenerarla.

Este panorama, maquillado y transformado por la modernización de sus técnicas, ha sobrevivido cas intacto hasta nuestros días. En nuestras escuelas sigue sin haber ninguna asignatura que se llame Arquitectura en letras mayúsculas. Los sistemas audiovisuales primero, la industria cultural del espectáculo y la información de las redes después no han hecho más que agravar el problema. Confiamos en la imagen más que nunca y más que en ninguna otra cosa y la arquitectura no es ni una realidad desmenuzada ni simplemente una imagen como se le quiere hacer creer al gran público que hoy visita multitudinariamente las exposiciones sobre arquitectos famosos.

Siempre que visitamos una exposición de arquitectura debemos partir de un supuesto: la arquitectura no está allí más que de manera vicaria. Planos, maquetas, fotografías y documentos emulan edificios que están en su realidad física en otro lugar. Esos documentos son como las antiguas asignaturas, nos muestran aspectos parciales de las obras de arquitectura en secuencias temporales diferentes. Algunos son previos a la construcción del edificio -planos y modelados de trabajo-, algunos contemporáneos - detalles y fotos de construcción- y otros posteriores -fotografías y maquetas.

Entonces ¿dónde está la arquitectura? ¿Podemos encontrarla en algún lugar? Preguntas tan obvias parecen haber perdido hoy su respuesta y parece que nadie las quiera formular. Escribo estas líneas de regreso de un viaje con estudiantes y profesores de la Etsab por varias ciudades del sur de Francia. Estas notas quieren ser la reivindicación del viaje como experiencia didáctica de primer orden. Si en las aulas, como en un laboratorio, podemos aislar los diferentes aspectos que un edificio presenta e incluso podemos ocultar aquellos que presenten contradicciones con el relato general de una lección, la visita directa, el estar allí respirando el mismo aire en el que la arquitectura se produce nos instala en la simultaneidad que la arquitectura siempre ha sido.

El viaje ya le había servido como armazón a la novela por lo menos desde El Quijote. Su texto profundamente didáctico no nace de una teoría explícita sino que, por el contrario, son las diferentes escenas y episodios en los que vive su protagonista que destilan lo que su autor quiere decir. El Wilhelm Meister de Goethe recoge la experiencia que es seguida por los románticos alemanes y por sus sucesores desde Novalis hasta Tieck, desde Karl Philipp Moritz hasta Adalbert Stifter y Gottfried Keller y desde ahí hasta las novelas actuales de Peter Handke.

Encontrarse con la arquitectura sin la rigidez de las clases de historia, de construcción o de proyectos permite ver ejemplos de épocas alejadas de manera contemporánea ya que somos nosotros quienes los vemos ahora. La arquitectura puede así volver a ser lo que durante siglos ha sido: juicio crítico sobre la arquitectura del pasado. Es un pasado presentado, presente en sus ejemplos materiales. Los edificios que visitamos responden sin artificio ninguno a las preguntas que queramos hacerles. Es cierto que las construcciones no hablan por ellas solas, pero son la demostración misma de la arquitectura que sin ellas no sería más que una teoría.

Son también lugares que la historia ha cambiado. El anfiteatro de Arles estando donde siempre ha estado ya no está en una ciudad romana reconocible y comparándolo con el de Nimes, contemporáneo en su origen, podemos ver la diferente evolución de su emplazamiento tal como nos los encontramos hoy. Podemos ver hasta donde resiste la arquitectura frente a la ruina provocada por el tiempo y por el hombre, qué se puede perder sin que la arquitectura desaparezca del todo. Es importante también ver si lo que los manuales nos habían explicado respondía a criterios demasiado generales y ejercitarse en encontrar ese no se qué único que lo hace diferente de los demás.

Vemos que en tiempos diferentes las estrategias desplegadas por la arquitectura han sido distintas. Lo romano y lo románico, tan próximos en tantas cosas, tienen una narrativa casi opuesta, a la imagen arquitectónica cerrada e indestructible del imperio se contrapone el despliegue figurativo simbólico del juicio final en la portada de Saint Trophime de Arles donde un Dios todopoderoso separa a los justos de los pecadores. A la arquitectura le corresponde mostrar tanto el cielo con sus coros celestiales, como el infierno con sus cadenas, sus calderas y sus demonios.

Al llegar a la arquitectura del último siglo llama poderosamente la atención encontrar más diferencias que similitudes en breves lapsos de tiempo. Una exposición de Jean Prouvé junto a un edificio de Frank Gehry. ¿Qué se habrían dicho si se hubiesen encontrado en la terraza de un café? ¿Se habrían insultado o simplemente se habrían ignorado? EI primero intentando pesar cada vez menos, ser cada vez más esencial, el segundo retorciendo el concepto hasta convertirlo en artificio. Son como las poéticas contrapuestas de San Juan de la Cruz y de Góngora.

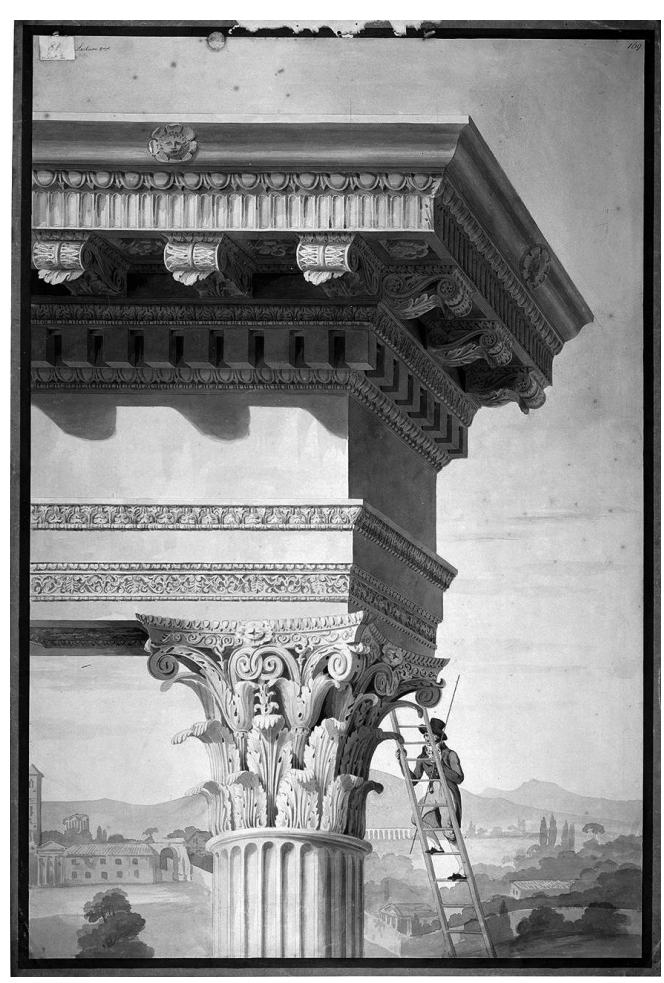
Un alumno de John Soane en Roma midiendo un
capitel corintio

El viaje hay que planificarlo. Es un espacio de trabajo que debería sustituir a algunos espacios docentes obsoletos. Los lugares visitados tienen que provocar afinidades y contrastes tanto de época como de contenido. Hay que buscar también y esta cuestión es la más delicada, la manera de explicar y aplicar la experiencia tras el regreso. Fotografías y dibujos, claro, pero no es suficiente. Hay que conseguir que el viaje se convierta en una herramienta didáctica insustituible, que ayude a valorar lugares y oportunidades, pesos y escalas, proporciones y desproporciones, colores y materiales.

El viaje nos hace cambiar bruscamente de lugar. Visitamos geografías y ciudades en las que habitualmente no vivimos y eso nos ha de servir para incorporar la vida a nuestra idea de la arquitectura. Con demasiada frecuencia enseñamos arquitectura como una disciplina aislada, encerrada en ella misma o en una campana de vacío, haciéndola aparecer ajena a la vida de los lugares en los que se produce. Esto no debería ser así. Cómo son y cómo nos miran las gentes que deambulan por las calles, cual es el tipo de relación de esas gentes con el espacio público, que tipo de actividades comerciales desarrollan, como visten, como se protegen del clima, que vino beben, que comen, todo esto es también arquitectura. En su relato de una visita a San Geminiano Walter Benjamín habla de cómo la ausencia de casa propia hace que el viajero convierta el tiempo del viaje en un palacio. Eso es lo que tenemos que conseguir.

ENRIQUE GRANELL es Doctor Arquitecto y Profeso titular del Departamento de Teoría e Historia de la Arquitectura y Técnicas de Comunicación de la ETSAB, Universitat Politècnica de Catalunya (UPC) 